\title{
O GEOPROCESSAMENTO APLICADO AO PLANEJAMENTO URBANO: ESTUDO DE CASO DA PAISAGEM DE ITAJAÍ NO CONTEXTO DA INUNDAÇÃO DE 2011
}

\author{
LONGARETE, C. ${ }^{1} \&$ MARENZI, R.C. ${ }^{1}$ \\ 1. Laboratório de Conservação e Gestão Costeira. Universidade do Vale do Itajaí - UNIVALI. \\ *Corresponding author: longarete@univali.br
}

\begin{abstract}
Longarete, C. ${ }^{1}$ (2017). Geoprocessing applied to urban planning: Itajaí landscape case study in the context of the 2011 flood, Brazil. Braz. J. Aquat. Sci. Technol. 21(2). eISSN 1983-9057. DOI: 11139/bjast.v22n2. The county of Itajaí, located on the central-north coast of Santa Catarina, is known nationally for the magnitude of its floods. It represents an area of high socioeconomic and environmental complexity. In this way, it was sought to know which land use and coverage has the areas most affected by the flood of 2011 , last great flood with registration in the county. For this, an analysis of the land use and coverage of the county was carried out, using images from Landsat 8 satellite and aerial photogrammetric images available by the state of Santa Catarina. After the classification and quantification of the uses were intersected with the flood polygon available by the Civil Defense of the county, and quantified the affected areas of each class of use. As a result, the predominant use of Itajaí is related to the class of Seminatural Space, followed by Natural Space, Agricultural Areas, Residential Area and Infrastructure and Commercial Units. Finally, when overlapping with the flood polygon, the most affected use is referred to the class of Seminatural Space, Residential Area, Agricultural Areas, Infrastructure and Commercial Units, and lastly, the least affected class was Natural Space.
\end{abstract}

Key Words: Land use and coverage, Flood, Itajaí, Territorial Analysis.

\section{INTRODUÇÃO}

A zona costeira é considerada um ambiente de alta complexidade em que residem grande parte da população mundial. O processo de crescimento urbano, por vezes, sem planejamento é um dos principais geradores de cenários de inundações, que constitui um dos principais desastres nas cidades brasileiras (Tucci, 2007). Entretanto, as inundações em ambientes urbanos são um resultado não apenas de variáveis meteorológicas, mas sim da soma destas com as atividades humanas não planejadas (Piper, 2014; Flannery et al., 2015; Moel et al., 2011). Por isso, entender o uso e a ocupação que se dá nesse espaço torna-se uma importante ferramenta na busca pela mitigação dos impactos, no âmbito do planejamento urbano.

O município de Itajaí, localiza-se no litoral centro-norte de Santa Catarina, e por suas características geográficas sofre com inundações desde o início de sua colonização (Nogueira et al., 2009). É o último município do baixo Vale do Itajaí, no qual ao longo de 150 anos de registros foi afetado por aproximadamente 67 inundações de médias a grandes proporções (Nogueira et al., 2009; Cunha \& Eyerkaufer, 2013; Espíndola et al., 2011). Segundo Tucci (2005), as inundações de Itajaí são do tipo de áreas ribeirinhas, mas que também sofrem influência de processos urbanos, com uma ocupação desordenada.
Dentre todas as inundações ocorridas em Itajaí destacam-se quatro grandes datas, 1983, 1984, 2008 e 2011. Foram inundações geradas por eventos extremos de chuva, no qual, devido à falta de monitoramento, apenas o ano de 2011 possui dados levantados da área afetada. Além disso, o município de Itajaí junto com Joinville e Florianópolis, representa uma das três regiões com maior risco do estado de Santa Catarina, segundo o Macro Diagnóstico da Zona Costeira do Brasil (BRASIL, 2009).

Por isso, o presente trabalho tem como objetivo relacionar os usos e cobertura do solo com as áreas expostas à inundação em Itajaí, para que se possa conhecer quais os usos mais afetados por estes eventos, e assim poder ser utilizado como base para o desenvolvimento de medidas mitigadoras, a fim de diminuir os riscos que sofre a população destas áreas.

Para isso, primeiramente foi realizado um levantamento do uso e cobertura do solo, com base na metodologia do programa CORINE Land Cover (EEA, 1999). Estes resultados possibilitam saber quais os principais usos do município e sua distribuição no território. Na sequência são sobrepostos a este levantamento dados da inundação de 2011, disponibilizados pela Defesa Civil do município, para que sejam intersectados, e assim esclarecer quais os usos mais afetados pelas cheias, entendendo assim, quais os usos localizados nas áreas mais expostas do município. 


\section{O cenário do planejamento urbano no Brasil}

O planejamento urbano, de uma maneira simplista, pode ser entendido como um método de organizar os elementos urbanos com o intuito de melhorar a dinâmica da sociedade para determinado objetivo.

Historicamente teve um avanço significativo no final da Segunda Guerra Mundial. O qual, profissionais de diversas áreas (sociais, história, direito, economia, etc.) propuseram um método integrador de planejar distinto do realizado antes, por profissionais apenas urbanistas. Este, deu origem então ao planejamento urbano moderno (Lima \& Mendonça, 2001).

A zona costeira é um ambiente no qual reside grande parte da população mundial. Em termos ambientais é um espaço singular, por abrigar muitos ecossistemas de relevente importância e certa fragilidade. Por isso, o crescimento urbano das cidades costeiras, somado à fragilidade destes ambientes têm gerado cenários de vulnerabilidade no mundo (De Sherbinin et al., 2007).

Estar na costa ou próximos a grandes rios facilita o comércio entre cidades. Porém, com o crescimento urbano, as mesmas estão se tornando zonas de risco frente a eventos climáticos como, ciclones, inundações, erosões costeiras, aumento do nível do mar, etc. (De Sherbinin et al., 2007).

No Brasil o processo de urbanização acelerado ocorreu em meados da década de 60 , gerando, como consequência da falta de investimento, uma população urbana quase que sem infraestrutura (Tucci, 2007).

As inundações urbanas são um dos principais eventos geradores de impacto sobre a sociedade (Tucci, 2007). Contudo, podem ser entendidas como um resultado não apenas de elementos meteorológicos e hidrográficos, mas sim, da junção destes com as atividades humanas, destacando-se o crescimento não planejado e em planícies aluviais (Piper, 2014; Flannery et al., 2015; Moel et al., 2011).

Sabe-se então que a rápida transformação do solo gera populações vulneráveis, sobretudo em regiões já expostas devido às suas características geográfias. Para Jha et al. (2012), a urbanização projeta uma tendência inevitável, incontrolável e negativa, com potencial para aumentar o risco de inundações.

Desta forma, torna-se imprescindível conhecer o perfil de uso e cobertura do solo dessas localidades. Uma vez que, são elementos chave para descrever o ambiente em relação aos processos naturais e atividades humanas (Mendoza et al., 2013; Alberico et al., 2014).

Para Monte-Mór (2006), o planejamento urbano se materializa no zoneamento e controle do uso do solo. Ao conhecer as caracterísitcas de uso, segundo Tucci (2007), é necessário desenvolver um processo de regulação, por meio de um plano diretor que leve em consideração as áreas inundáveis.

\section{O Geoprocessamento na área do planejamento urbano}

O termo Geoprocessamento de forma geral, é entendido como a capacidade de processar informações. Pode ser considerado um conjunto de tecnologias, métodos e processos para o processamento digital de dados e informações geográficas (Pereira \& Silva, 2001). Tendo em vista que o planejamento urbano visa ordenar os espaços desde uma visão econômica, social e ambiental, para que os processos realizados tenham fluidez e resulte em um ambiente saudável a todos que o usufruem, o geoprocessamento tem a função de auxiliar na junção destes dados e informações à variável espacial.

Para Cardovez (2002), são inúmeras as vantagens em incoporar a geotecnia na gestão municipal. Destacam-se, a escolha dos melhores locais para construção de infraestrutura pública; mapeamento do sistema de transporte público; levantamento de espaços vazios no município, de ocupações irregulares, e de áreas de risco ambiental, entre outras. Em um estudo realizado por Moura (2002) na cidade de Ouro Preto - Minas Gerais, concluiu-se que a utilização de ferramentas de geoprocessamento facilitam a representação do tempo e espaço, e desta forma fazem com que sejam melhor analisados.

Além de conhecer o ambiente desde uma visão mais ampliada, segundo Farina (2006), o geoprocessamento tem a capacidade de acompanhar o movimento do meio ambiente (natureza e sociedade) e integrar diversas fontes de informação quando desejado. Esta mesma autora menciona que no âmbito ambiental, as técnicas de geoprocessamento vêm para fornecer subsídios à criação de cenários urbanos dentro de uma perspectiva de sustentabilidade.

Para o caso das inundações, o geoprocessamento permite realizar diversas análises e predições. É possível delimitar áreas que foram atingidas por inundações passadas, além de, por meio de dados topográficos, saber quais áreas são mais expostas (Tucci, 2007).

\section{Processamento digital de imagens e Sensoriamento remoto}

O Processamento Digital de Imagens (PDI), de forma sucinta, pode ser entendido como a manipulação de imagens obtidas por métodos computacionais. Tem como objetivo melhorar o aspecto visual de certas feições estruturais de acordo com o interesse do usuário, fazendo com que facilite sua interpretação (INPE, 2015). 
As principais operações que se podem aplicar sobre uma imagem passam pelas etapas de aquisição da imagem, seu processamento e exibição. Tais etapas podem ser vistas como o sistema do PDI. A aquisição é realizada por algum dispositivo, uma câmera por exemplo. O processamento propriamente dito é realizado em um hardware, e envolvem diversas técnicas que vão de acordo com o objetivo da análise que se está realizando. Por fim, a etapa de exibição, são em muitas vezes, feitas por meio da produção de mapas (Marques Filho \& Vieira Neto, 1999; Queiroz \& Gomes, 2001).

Já o Sensoriamento Remoto, termo que vem sendo aprimorado desde seu surgimento no início dos anos 1960, atualmente é conceituado como uma ciência que possui o objetivo de desenvolver técnicas de obtenção de imagens da superfície terrestre, por meio de respostas das interações da radiação eletromagnética com os materiais terrestres (Meneses \& Almeida, 2012).

Segundo Gonzales et al. (2010), em termos gerais não há mais nenhuma área de empreendimento técnico que não seja influenciada pelo PDI. Imagens processadas têm sido aplicadas em diversas áreas do conhecimento.

Para o caso das inundações, a utilização das técnicas de PDI e Sensoriamento Remoto, contribuem efetivamente nas análises desde o mapeamento das áreas atingidas, até a prevenção e controle (Hora \& Gomes, 2009). No que diz respeito às mudanças no uso do solo, o sensoriamento remoto permite a análise temporal de imagens registradas em datas diferentes, possibilitando acompanhar essa evolução ao longo do tempo. Ao cruzar tais imagens com informações técnicas, dentro de um Sistema de Informações Geográficas, possibilita-se a realização de levantamentos e análises com fins de planejamento de um espaço. Estas atividades constituem-se técnicas de geoprocessamento (Fitz, 2008).

\section{MATERIAIS E MÉTODOS}

\section{Área de Estudo}

O município de Itajaí está localizado na costa do litoral centro-norte do estado de Santa Catarina-Brasil (Figura 1). Segundo IBGE (2010), Itajaí possui uma população de aproximadamente 183.373 habitantes em uma área de $288.286 \mathrm{~km}^{2}$, totalizando uma densidade demográfica de 636,11 hab $/ \mathrm{km}^{2}$. Possui o segundo PIB per capita do estado, e é o $42^{\circ} \mathrm{IDH}$ do Brasil. Localiza-se na desembocadura do rio ItajaíAçú, um dos maiores rios do estado. Está no baixo vale da bacia hidrográfica do rio Itajaí, constituída por 58 municípios. É considerada uma cidade plana, pois $54,26 \%$ da sua superfície apresenta declividade inferior a $2^{\circ}$. É um município urbano, uma vez que $96,2 \%$ da população vive em áreas urbanizadas. Estas áreas encontram-se quase toda sua totalidade nas áreas com as menores declividades. Sua economia possui forte relação com atividades pesqueiras e portuárias.

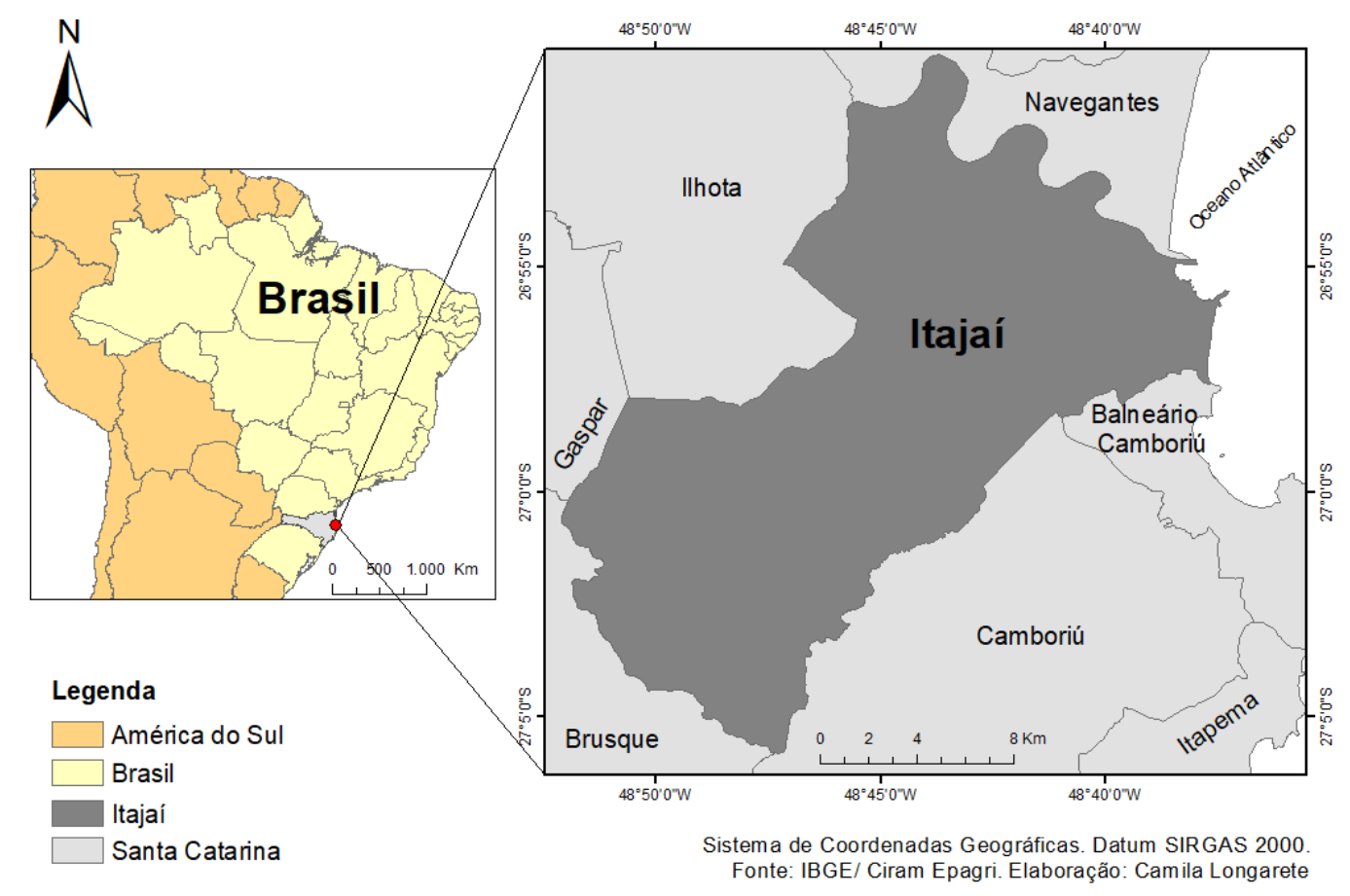

Figura 1 - Localização da área de estudo. 


\section{Método}

Este trabalho apresenta um estudo de caso, onde são apresentados produtos cartográficos e suas respectivas análises para a cidade de Itajaí - Santa Catarina, na área de planejamento urbano, utilizando técnicas de processamento digital de imagens e sensoriamento remoto.

Para isto, em 4 etapas, foi utilizado os softwares de Processamento Digital de Imagens e Sensoriamento Remoto, ArcGis e QGIS, para trabalhar complementos de técnicas de Sensoriamento Remoto.

Inicialmente, na etapa de pré-processamento, foram obtidas as imagens e inseridas nas mesmas, os dados da área de estudo. Na sequência, etapa dois, que concentra métodos de Processamento Digital de Imagens (PDI), foram realizadas composição de bandas coloridas de imagens, recorte da área de trabalho e a preparação da Carta Imagem. Na terceira etapa, o sensoriamento remoto, foram extraídas informações qualitativas das imagens orbitais e das fotografias utilizadas. Para isso, realizou-se uma classificação manual do uso e cobertura do solo da área de estudo, com base nas classes de uso do CORINE Land Cover (EEA, 1999). Por fim, na etapa quatro, foram elaborados os produtos cartográficos e suas respectivas análises.

\section{RESULTADOS E DISCUSSÃO}

$\mathrm{Na}$ etapa de pré-processamento os seguintes dados foram coletados: Aquisição da cena correspondente à área de estudo do Satélite Landsat 8/OLI com resolução espacial de $30 \mathrm{~m}$, na órbita 220/079, 21 imagetns aerofotogramétricas da Secretaria de Desenvolvimento Econômico Sustentável do estado de Santa Catarina - SDS, com resolução de 0,39 $\mathrm{cm}$, e polígono que representa a inundação de 2011 junto à Defesa Civil do município. As imagens da SDS são oriundas de um levantamento LIDAR realizado em 2011. Para as imagens Landsat (figura 2) foi realizado composição real de tcores para classificação supervisionada no software QGIS 2.18. Na sequência, as imagens LIDAR (figura 3) foram mosaicadas e utilizadas para classificação manual da área urbana por meio do software ArcGis10.2. Cabe lembrar que não foi necessário realizar georreferenciamento, nem aplicação de filtros na presente análise.

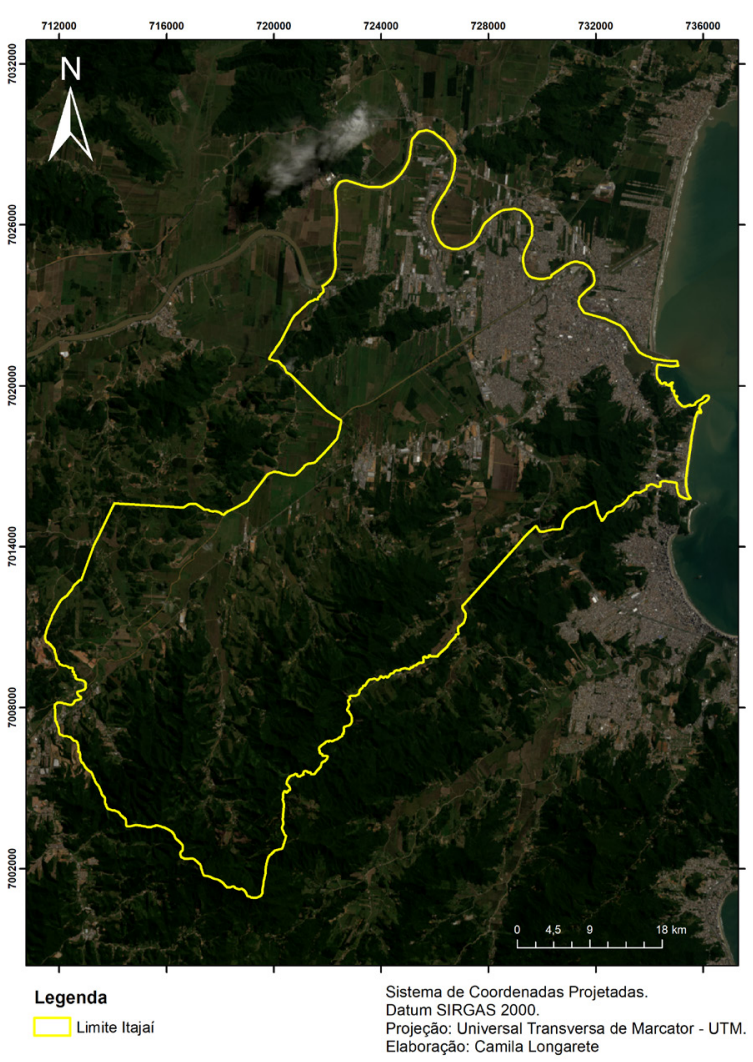

Figura 2 - Limite da área de estudo e imagens Landsat $8 \mathrm{com}$ composição colorida real.

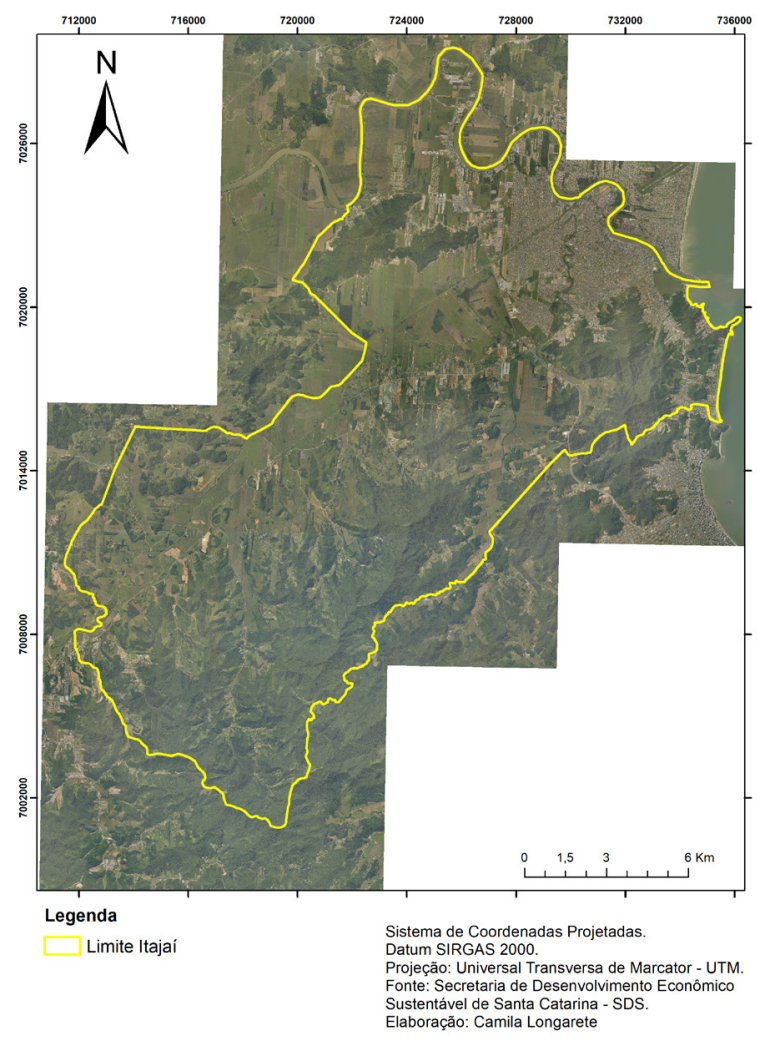

Figura 3 - Limite da área de estudo e mosaico de 21 imagens LIDAR. 
Por meio da classificação supervisionada foi classificado as áreas de Espaços Naturais, Áreas Agrícolas e Espaços Seminaturais. Estas classes são adaptadas do programa CORINE Land Cover, o qual conceitua-se para Espaços Naturais, áreas que não têm sofrido intervenção antrópica ou é imperceptível; Áreas Agrícolas, correspondem às áreas com atividades de agricultura, florestação e extração natural; e os Espaços Seminaturais, são as áreas naturais que têm sofrido com algum tipo de intervenção antrópica, mas que não foi ainda edificada.

Na sequência, nas áreas classificadas como urbanas, foram mais uma vez classificadas, desta vez com as imagens LIDAR, em uma escala de $3.000 \mathrm{~m}$, das quais permitem melhor identificação dos elementos a serem classificados, devido à sua resolução. Nesta etapa foram mapeadas as classes Área Residencial e Infraestrutura e Unidades Comerciais, ambas adaptadas também do CORINE Land Cover. Estas classes respectivamente são descritas como áreas ocupadas por diversos tipos de habitações, e espaços cobertos por indústrias, comercio, infraestrutura de transporte, instalações públicas etc.

Desta forma, como resultado, a classe de Espaço Seminatural foi a que apresentou maior área, seguidas das classes de Espaço Natural, Áreas Agrícolas, Área Residencial e Infraestrutura e Unidades Comerciais (figura 4 e tabela 1).

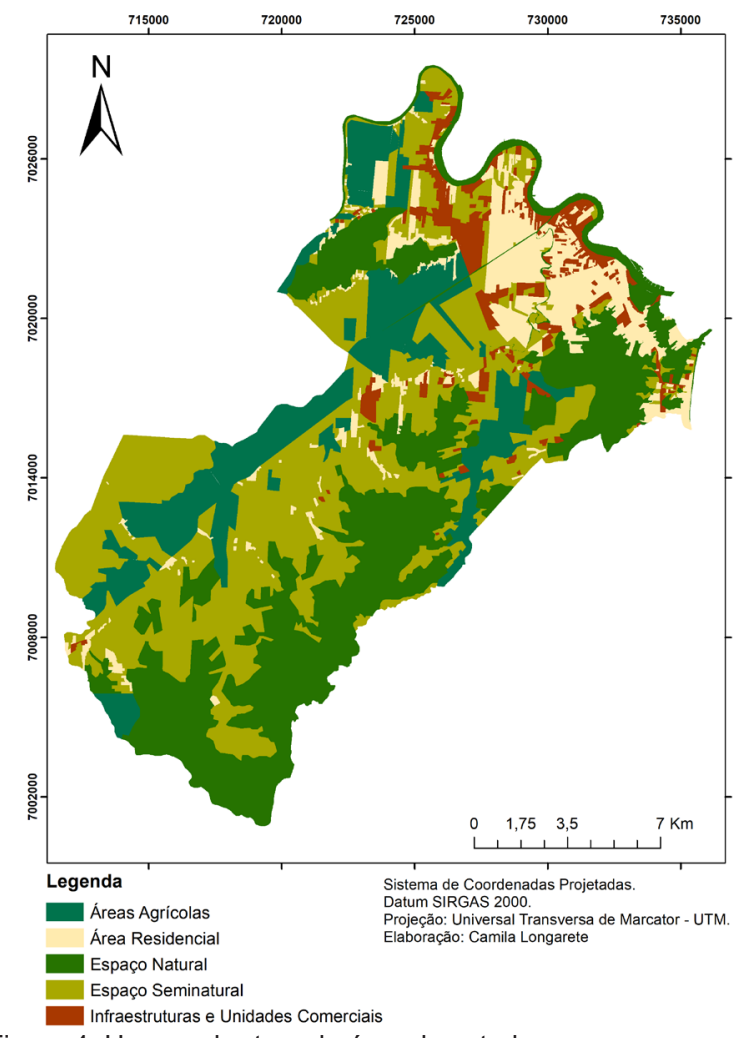

Figura 4: Uso e cobertura da área de estudo.
Tabela 1 - Quantificação das classes de uso e cobertura do solo de Itajaí.

\begin{tabular}{r|r|r} 
Uso e Cobertura do Solo & Área $\left.\mathbf{( k m}^{2}\right)$ & \% uso e cobertura \\
\hline \hline Área Agrícola & 47.330 .088 & 16,61 \\
\hline Infraestrutura e Uni. Comerciais & 13.163 .027 & 4,62 \\
\hline Área Residencial & 27.474 .411 & 9,64 \\
\hline Espaço Seminatural & 103.632 .879 & 36,36 \\
\hline Espaço Natural & 93.416 .825 & 32,78 \\
\hline
\end{tabular}

O município de Itajaí tem sua população predominantemente vivendo em área urbana (IBGE, 2010), que se concentra na região costeira de seu território. Pode-se então verificar que a concentração da classe Área Residencial se localiza a nordeste da sua área territorial, assim como a classe de Infraestrutura e Unidades Comerciais. A classe de Espaço Natural corresponde, sobretudo, às áreas de morrarias do município. Vale destacar que, devido à altimetria, estas são áreas mais difíceis de serem ocupadas, por isso, têm-se mais áreas preservadas. As Áreas Agrícolas concentram-se na zona rural do município, e são representadas principalmente por rizicultura e plantação de eucaliptos. Finalmente, a classe de Espaço Seminatural refere-se às áreas alteradas, mas que ainda não possui um uso determinado. Estão muito próximas às áreas agrícolas e aos Espaços Naturais, visto que são resultados do avanço do homem sobre a natureza.

Para quantificar quais os usos mais afetados pela inundação de 2011, os usos e cobertura mapeados na etapa anterior, foram sobrepostos à área de inundação levantada pela Defesa Civil do município (figura 5).

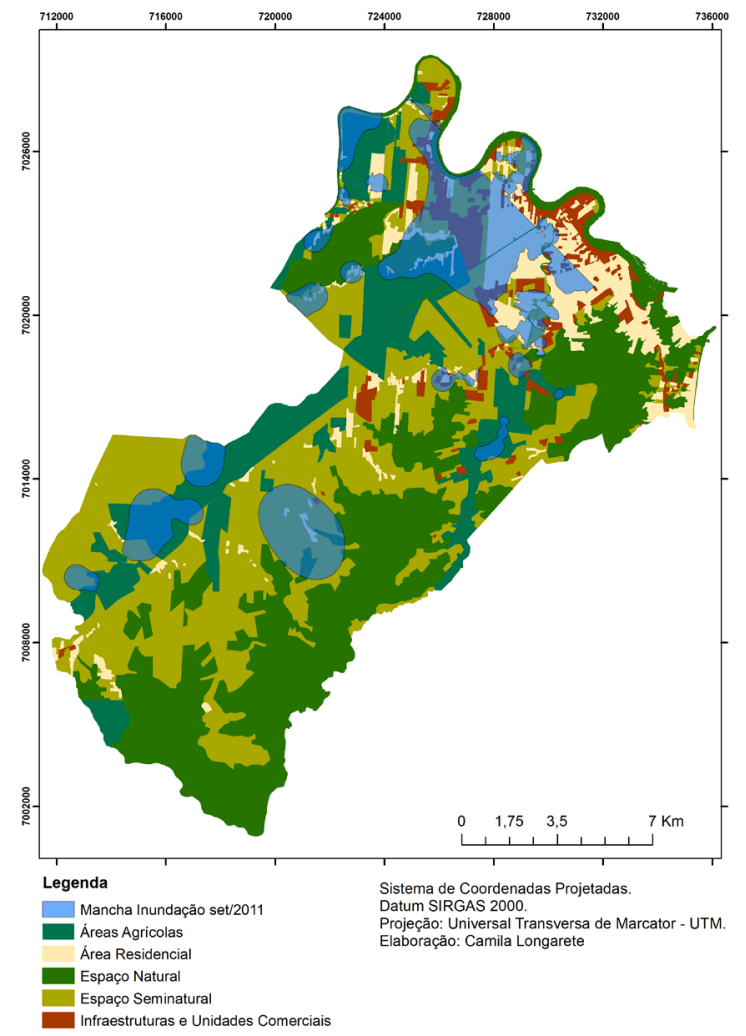

Figura 5: Sobreposição dos usos e cobertura do solo com a área de inundação do ano de 2011. 
Neste evento a inundação afetou uma área aproximada de $48,863762 \mathrm{~km}^{2}$ e o uso mais afetado foi o Espaço Seminatural, seguido por Área Residencial, Área Agrícola, Infraestrutura e Unidades Comerciais, e por fim Espaço Natural, visualizados na tabela 2.

\begin{tabular}{r|r|r} 
Uso e Cobertura do Solo & Área afetada $\left.\mathbf{( k m}^{2}\right)$ & \% de área afetada \\
\hline \hline Área Agrícola & 9,411978 & 19,54 \\
\hline Infraestrutura e Unidades Comerciais & 5,216514 & 10,83 \\
\hline Área Residencial & 10,530148 & 21,86 \\
\hline Espaço Seminatural & 18,229126 & 37,85 \\
\hline Espaço Natural & 4,776355 & 9,92 \\
\hline
\end{tabular}

Tabela 2: Quantificação das classes de uso e cobertura do solo de Itajaí intersectadas com a mancha de inundação do ano 2011.

\section{CONCLUSÃO}

O uso do geoprocessamento para a presente análise foi indispensável por permitir as sobreposições das camadas, cálculos de área e classificação dos elementos terrestres, presente na área de estudo. Por isso, os objetivos foram alcançados, uma vez que foi possível verificar, qual o uso mais afetado pela inundação proposta.

É importante ressaltar que nesta análise, que envolveu uso do solo e inundação, as áreas afetadas não são restritamente relacionadas apenas ao uso. É necessário, conhecer a topografia da área para que se possa tomar melhores conclusões. No caso do presente estudo, a classe de Espaço Natural foi a menos afetada, visto que são áreas mais elevadas. Já a Área Residencial e Infraestrutura e Unidades Comerciais estão localizadas na região mais próxima ao rio Itajaí, com topografia plana. Para o caso das classes de Espaço Seminatural e Áreas Agrícolas, também estão em regiões planas, mas como são classes bem distribuídas no território de análise, este fato, também influencia no resultado.

Assim, pode-se utilizar tal análise para trabalhos que visem desenvolver medidas mitigadoras e adaptativas frente às inundações, no sentido de fiscalizar a ocupação residencial e de serviços nas áreas mais afetadas pela inundação. Tais medidas devem estar presentes no Plano Diretor do município, por ser o instrumento regulador mais importante do desenvolvimento da cidade.

Para trabalhos futuros recomenda-se uma análise da evolução do uso e cobertura do solo ao longo do tempo, para entender o perfil de ocupação do município. Pode-se citar a resolução da imagem do satélite Landsat 8 como uma limitação, pois dificulta a classificação do solo, e como vantagem o acesso as imagens aerofotogramétricas de boa resolução, que foram essenciais para classificação da área urbana.

\section{REFERÊNCIAS}

Bertin, J. 1967. Sémiologie graphique. P. 8-13. Paris: mouton.

Rosette, A. C., Menezes, P. M. L. 2011. Erros comuns na cartografia temática. Rio de Janeiro: UFRJ, 1-9.

Brasil.2009. Macrodiagnóstico da Zona Costeira e Marinha do Brasil. Ministério do Meio Ambiente.

Cardovez, J. C. G. 2002. Geoprocessamento como ferramenta de gestão urbana. I Simpósio Regional de Geoprocessamento e Sensoriamento Remoto. Aracaju/SE, 17 e 18 de outubro.

Cunha, A. \& Eyerkaufer, M. L. 2013. Custos da prevenção e reconstrução em gestão de risco: um estudo de dois municípios do alto Vale do Itajaí (SC). Revista Eletrônica do Alto Vale do Itajaí REAVI. 2(1).

De Sherbinin, A.; Schiller, A. \& Pulsipher, A. 2007. The vulnerability of global cities to climate hazards. Environment \& Urbanization Copyright.International Institute for Environment and Development (IIED). 19(1):39-64. DOI: 10.1177/0956247807076725.

EEA- Agência Europeia do Ambiente. 1999. CORINE Land Cover techinical guide. Copenhagen, EEA.

Espíndola, M. A; Nodari, E.S \& Lopes, A.R.S. 2011. Considerações sobre desastres socioambientais no Vale do Itajaí-SC em 2008. IX Encontro Nacional da ECOECO, Brasília-DF.

Farina, F. C. 2006. Abordagem sobre as técnicas de geoprocessamento aplicadas ao planejamento e gestão urbana. Cadernos EBAPE.BR, 4(4): 1-13.

Fitz, P. R. 2008. Cartografia Básica. São Paulo-SP. Oficina de Textos, 143p.

Flannery, W.; Lynch, K. \& Ó Cinnéide, M.2015. Consideration of coastal risk in the Irish spatial planning process. Land Use Policy. 43.

Jha, A. K.; Bloch, R.; Lamond, J. 2012. Cidades e Inundações: Um guia pra a gestão integrada do risco de inundação urbana para o século XXI. Banco Internacional para Reconstrução e Desenvolvimento - Associação de Desenvolvimento Internacional/ Banco Mundial.

Hora, S. \& Gomes, R. 2009. Mapeamento e avaliação do risco a inundação do rio Cachoeira em trecho da área urbana do município de Itabuna. Sociedade \& Natureza, Uberlândia: $57-75 p$.

INPE - Instituto Nacional de Pesquisas Espaciais. Processamento Digital de Imagens. 2015. Disponível em: www.inpe.br. Acesso em: 05 de setembro de 2018.

Lima, C. A., Mendonça, F. 2001. Planejamento urbanoregional e crise ambiental: Região Metropolitana de Curitiba. São Paulo em perspectiva. 15 (1): 135-143. 
Meneses, P. R. \& Almeita, T. (org.). 2012. Introdução ao processamento de imagens de sensoriamento remoto. Brasília: UnB, 33p.

Marques Filho, O. \& Vieira Neto, H. 1999. Processamento Digital de Imagens. Rio de Janeiro: Brasport.

Monte-Mór, R. L. 2006. As teorias urbanas e o planejamento urbano no Brasil. Economia regional e urbana. Contribuições teóricas recentes. Belo Horizonte, Editora UFMG: 61-85.

Moura, A. C. 2003. Geoprocessamento aplicado ao planejamento urbano e à gestão do patrimônio histórico de Ouro Preto-MG. In: Congresso Brasileiro de Cartografia, 21, 2003, Rio de Janeiro. Anais. Rio de Janeiro: Sociedade Brasileira de Cartografia:1-9.

Nogueira, C. W., Gonçalves, M. B., \& Oliveira, D. 2009. O enfoque da logística humanitária no desenvolvimento de uma rede dinâmica para situações emergenciais: o caso do Vale do Itajaí em Santa Catarina. InAnais do XXII Congresso de Pesquisa e Ensino em Transportes.

Pereira, G. C.; Silva, B. N. 2001. Geoprocessamento e urbanismo. Teoria, Técnicas, Espaços e Atividades: Tema de Geografia Contemporânea.

Piper, G. 2014.Balancing flood risk and development in the flood plain: the Lower Thames Flood Risk Management Strategy. Ecohydrology \& Hydrobiology. 14(1): 33-38.

Queiroz, J. E. R. \& Gomes, H. M. 2001. Introdução ao Processamento Digital de Imagens. RITA: Instruções para preparação de documentos em Word. 8(1).

Tucci, C.E.M. 2005.Gestão de águas pluviais urbanas. Programa de Moderização do Setor de Saneamento, Secretaria Nacional de Saneamento Ambiental, Ministérios das cidades. Global Water Partnership/World Bank/Unesco.

Tucci, Carlos EM. 2007. Inundações urbanas. Porto Alegre: ABRH/RHAMA. V 11. 